\title{
Fatigue crack growth behavior in gradient microstructure of hardened surface layer for an axle steel
}

\author{
Shijia Zhang ${ }^{\mathrm{a}, \mathrm{b}}$, Jijia Xie ${ }^{\mathrm{a}, \mathrm{b}}$, Qingqing Jiang ${ }^{\mathrm{a}, \mathrm{b}}$, Xiaole Zhang ${ }^{\mathrm{a}}$, Chengqi Sun ${ }^{\mathrm{a}, \mathrm{b}}$, Youshi Hong ${ }^{\mathrm{a}, \mathrm{b}, *}$ \\ ${ }^{a}$ LNM, Institute of Mechanics, Chinese Academy of Sciences, Beijing 100190, China \\ b School of Engineering Science, University of Chinese Academy of Sciences, Beijing 100049, China
}

\section{A R T I C L E I N F O}

\section{Keywords:}

Fatigue crack growth

Surface strengthening

Gradient microstructure

Residual stress

Crack arrest

\begin{abstract}
A B S T R A C T
This paper experimentally investigated the behavior of fatigue crack growth of an axle steel with a surface strengthened gradient microstructure layer. First, the microstructure, residual stress and mechanical properties were examined as a function of depth from surface. Then the fatigue crack growth rate was measured via three point bending fatigue testing. The results indicated that fatigue crack growth rate decelerated first and then accelerated with the increase of crack length within the gradient layer. Especially, the fatigue crack was arrested in the gradient layer under relatively low stress amplitude due to the increase of threshold value for crack growth within the range of $3 \mathrm{~mm}$ from surface. Based on these results, the parameters of Paris equation and the threshold value of stress intensity factor range within the gradient layer were determined and a curved surface was constructed to correlate crack growth rate with stress intensity factor range and the depth from surface. The effects of microstructure, residual stress and surface notch on the crack growth behavior were also discussed.
\end{abstract}

\section{Introduction}

Fatigue failure is one of the main failure modes for engineering components, which has been investigated systematically since the 1860s. A large number of studies suggested that the fatigue strength of a material is proportional to its tensile strength and the fatigue crack that results in final failure usually initiates at the surface of the material [1-3]. In order to upgrade the fatigue strength of engineering materials/components, investigators have used surface strengthening techniques in the applications of aviation, automobile and high-speed railway [4-9]. The methods of surface treatment, such as shot peening, nitriding and surface induction, produce a strengthened surface layer which always possesses a gradient feature of microstructure and mechanical behavior including residual stress from the surface to the interior of treated specimens or components. Such a gradient feature must influence the fatigue crack initiation and propagation for the specimens or components.

Fajkoš et al. [5] reported that the fatigue strength of an EA4T steel (25CrMo4) with surface induction treatment had an increase of $70 \%$ compared to that with standard heat treatment. Roland et al. [7] and Yang et al. [8] showed that a stainless steel with surface mechanical attrition treatment and a pure $\mathrm{Cu}$ with surface mechanical grinding treatment had higher fatigue strength than the original materials, especially in high cycle fatigue regime. Other articles [10-15] also reported similar results of different materials with various types of surface treatments. All these investigations attributed the enhancement of the fatigue strength for the treated specimens or components to the grain refinement and the compressive residual stress caused by surface strengthening treatment. It has been regarded that fatigue crack growth behavior is as important as fatigue strength in the fatigue performance for a material $[16,17]$. With regard to the fatigue strength and the fatigue crack growth rate for the materials with different grain sizes, many articles stated that the fatigue strength of the materials with fine grains is higher than that with coarse grains, whereas the fatigue crack growth rate of the materials with fine grains is higher than that with coarse grains due to the insufficient plastic deformation ability for the fine grain cases [18-21]. Xu et al. [22] performed fatigue crack growth experiments on the steels with almost the same chemical compositions but different microstructures of pearlite-ferrite, ferrite-bainite-martensite and tempered martensite. Their result showed that the smaller the grain size was, the faster the fatigue crack grew and the higher the threshold value of stress intensity factor range $\left(\Delta K_{\text {th }}\right)$ would be. Li et al. [23] studied the fatigue crack growth behavior by modified Paris equation on a pure titanium of three different grain sizes and got the similar result of grain size effect. Blochwitz et al. [24] noticed that not only grain size but also the grain boundary influenced the fatigue crack growth for face-centered cubic metals and stainless steels. They indicated that grain boundary had an effect on fatigue crack propaga-

\footnotetext{
* Corresponding author at: LNM, Institute of Mechanics, Chinese Academy of Sciences, Beijing 100190, China.

E-mail address: hongys@imech.ac.cn (Y. Hong).
} 
tion by changing the crack path. Besides the effect of microstructure, residual stress is another significant factor that affects the fatigue crack behavior of surface strengthened materials. It was reported that compressive residual stress caused by un-uniform plastic deformation within the gradient layer, improved the fatigue resistance of 316 stainless steel, pure $\mathrm{Cu}$ and other alloys [7-11] and the gradient distribution of residual stress induced extra difficulty in the analysis of fatigue crack growth [25-28]. Thus, traditional fatigue theories which can describe the fatigue crack growth behavior in homogeneous materials are no longer applicable for the materials with gradient surface layer. It was anticipated that the threshold value of crack growth $\Delta K_{\text {th }}$ and the parameters of Paris equation could vary at different depths within the gradient layer $[29,30]$. Nevertheless, the fatigue behavior of the metallic materials containing a surface layer with gradient feature of modified microstructure is still less reported in the literature, which is a challenging topic that requires in-depth investigation, due to the related unknown mechanism and the requirement in the fatigue design of gradient materials.

Therefore, the purpose of this paper is to intensively investigate the fatigue crack growth behavior in the gradient microstructure layer of surface strengthened material. The test material is a train axle steel with surface induction treatment. Three-point bending (TPB) fatigue experiments were performed to obtain the fatigue crack growth data along the gradient microstructure layer of the specimen. The influential factors of microstructure types, microhardness, tensile strength, and residual stress at different depths of the gradient layer were characterized and used to describe the distinct behavior of fatigue crack growth in the gradient layer. The phenomena of crack deceleration and crack arrest for the gradient material were specially discussed and the notch effect on the crack growth threshold was also addressed.

\section{Material and test methods}

\subsection{Material and specimens}

The material tested in this investigation is a medium carbon steel (S38C) obtained from a high-speed locomotive axle. The chemical compositions (wt\%) of this steel are: $0.42 \mathrm{C}, 0.31 \mathrm{Si}, 0.82 \mathrm{Mn}, 0.0072 \mathrm{P}$, $0.0084 \mathrm{~S}, 0.02 \mathrm{Al}, 0.0037 \mathrm{~N}, 0.0006 \mathrm{O}$ and Fe balance. The axle was previously processed by induction hardening (a surface strengthening method) and thus had a gradient feature of modified microstructure surface layer.

Tensile specimens (Fig. 1(a)) were cut from an axle section gradually from surface to $7.5 \mathrm{~mm}$ depth with one specimen every $1 \mathrm{~mm}$ in depth by wire electrical-discharge machining (WEDM). The specimen cut from a given depth keeps the microstructure at that location and a series of 8 specimens from surface to $7.5 \mathrm{~mm}$ depth maintains the gradient microstructure feature of the material. At each depth, four specimens were prepared, i.e. $8 \times 4=32$ specimens were used in the tensile testing. All specimens were ground and polished before testing. Then, they were tested to obtain the strength and the ductility at every $1 \mathrm{~mm}$ depth from the surface of the material.

Specimens used for fatigue crack growth tests were also cut from the surface layer of an axle section by WEDM and every specimen maintained the gradient microstructure feature of surface layer. A notch $(0.5 \mathrm{~mm}$ depth) was machined also by WEDM in the middle section of the specimen (hardened surface side) to lead crack initiation. The shape with the dimensions of the specimen is shown in Fig. 1(b) and (c).

\subsection{Test methods for microstructure, microhardness, residual stress and tensile strength}

The microstructure of the gradient surface layer was examined by optical microscopy. The examinations were from the surface to the interior of the material at $0.04 \mathrm{~mm}, 1 \mathrm{~mm}, 2 \mathrm{~mm}, 2.5 \mathrm{~mm}, 3 \mathrm{~mm}, 4 \mathrm{~mm}$, (a)
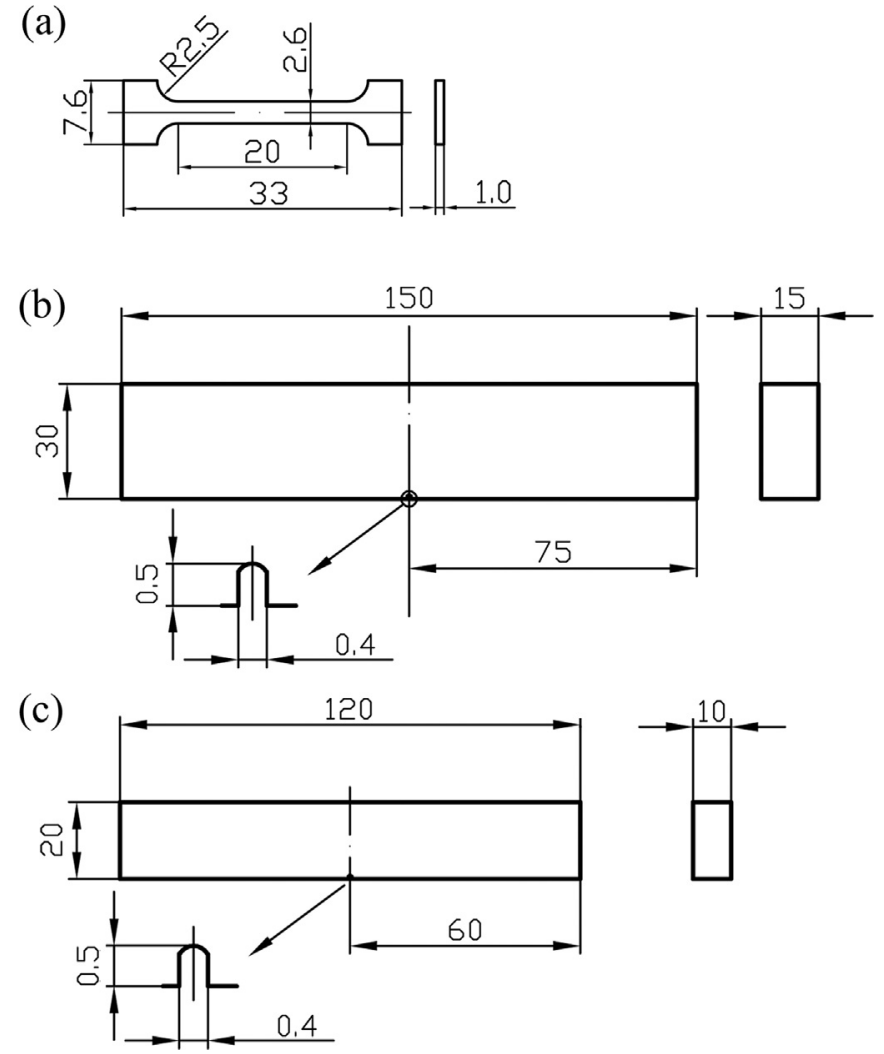

Fig. 1. Specimen shape and dimensions (in mm). (a) For tensile testing, (b) for SAL fatigue testing (loading span $120 \mathrm{~mm}$ ) and (c) for CAL fatigue testing (loading span $80 \mathrm{~mm})$.

$6 \mathrm{~mm}$ and $8 \mathrm{~mm}$ depth from surface. Five different locations were examined i.e. $5 \times 8=40$ samples were cut from the hardened surface layer accordingly and then polished and etched by $4 \%$ Nital.

The values of microhardness for the gradient surface layer were measured by using a microhardness tester. For this purpose, 5 samples were used and the measurements for each sample were from just underneath the surface down to $8 \mathrm{~mm}$ depth from the surface with the step of $0.5 \mathrm{~mm}$ between two measurements. The indentation load was $200 \mathrm{gf}$ and the load maintaining time was $15 \mathrm{~s}$.

The values of residual stress from the surface to the interior of the tested material were measured by using an X-Ray stress analyzer. Six SAL specimens (Fig. 1(b)) and six CAL specimens (Fig. 1(c)), three with induced notch and the other three without for each type, were used in this measurement. For notched specimens, the measurement location was from the notch root to the other end of specimen. For un-notched specimens, the measurement location was from the hardened surface to the other end of specimen.

The tensile tests on eight groups of specimens, with each group consisting of four ones (Fig. 1(a)), were performed by using an MTS testing machine (capacity $50 \mathrm{kN}$ ) at the tensile strain rate of $1.67 \times 10^{-4} \mathrm{~s}^{-1}$. Such specimens were cut successively from surface to different depths of $0.5 \mathrm{~mm}, 1.5 \mathrm{~mm}, 2.5 \mathrm{~mm}, 3.5 \mathrm{~mm}, 4.5 \mathrm{~mm}$, $5.5 \mathrm{~mm}, 6.5 \mathrm{~mm}$ and $7.5 \mathrm{~mm}$.

\subsection{Test method for fatigue crack growth measurement}

Fatigue crack growth testing was conducted at room temperature with TPB loading by means of step amplitude loading (SAL) method and constant amplitude loading (CAL) method. SAL testing was on an electromagnetic fatigue testing machine (EFTM) (Fig. 2), and CAL testing was on EFTM and MTS. The loading frequency was about $145 \mathrm{~Hz}$ for EFTM and $15 \mathrm{~Hz}$ for MTS. The stress ratio was 0.1 for both testing cases. The fatigue crack was perpendicular to the surface of the 


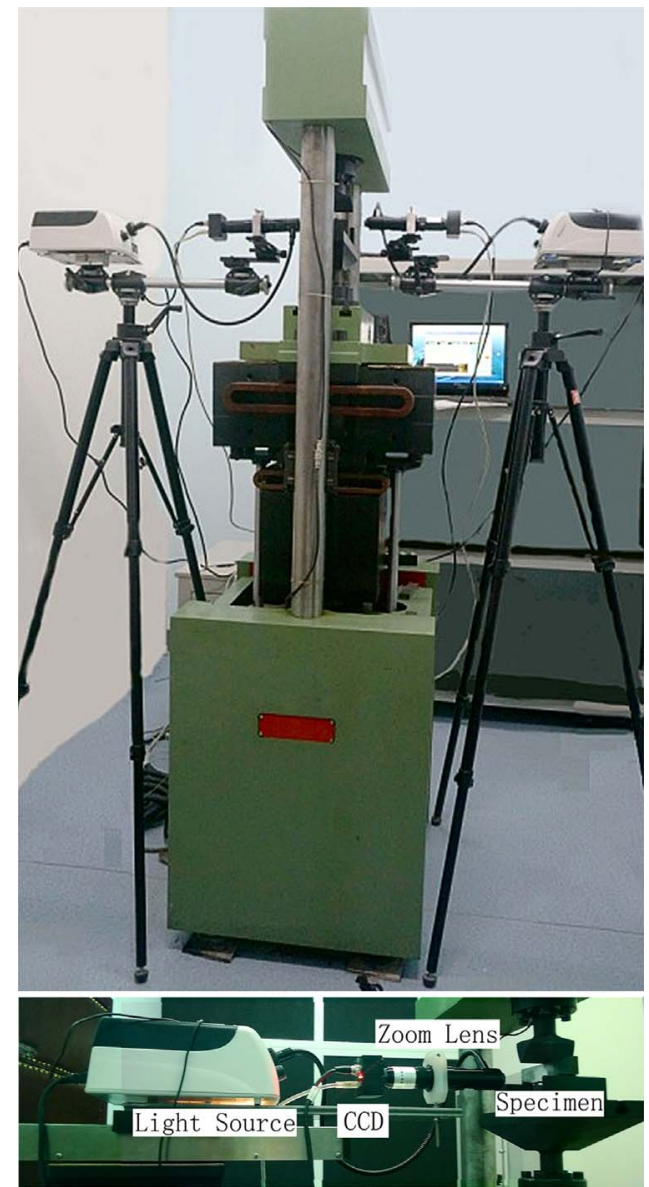

Fig. 2. Electromagnetic fatigue testing machine and in-situ optical observation system.

gradient layer and grew along the depth. When a crack grew with an increment of $0.1 \mathrm{~mm}$ under a cyclic loading level, the cycling was intermitted and the crack image was taken by an in-situ optical observation system (shown in Fig. 2). For CAL testing, the loading amplitude kept constant, which was large enough to keep the fatigue crack growing. For the sake of acquiring enough experimental data at each depth, SAL testing was performed and it was controlled in the following way. Each SAL specimen was tested under an initial loading amplitude according to the experimental design. If the length of a fatigue crack was without change after $10^{6}$ cycles at a given loading amplitude, then the amplitude level for the testing was increased with an increment of 10 or $20 \mathrm{MPa}$. At the stage of fatigue crack length beyond $10 \mathrm{~mm}$, the testing was terminated and the specimen was chilled in liquid nitrogen for $20 \mathrm{~min}$ then immediately reloaded to result in brittle fracture. Thus the border of fatigue crack was separated by the brittle cleavage fracture surface, which enabled the fatigue crack length measurement (average of five points of crack front measurements) on the fracture surface for the calibration of the surface measurements via the in-situ observation system.

We used Eqs. (1) and (2) [31] for calculating the value of stress intensity factor range $(\Delta K)$.

$\Delta K=\Delta \sigma \sqrt{\pi l} f\left(\frac{l}{b}\right)$

$f\left(\frac{l}{b}\right)=\frac{1}{\sqrt{\pi}} \frac{1.99-\frac{l}{b}\left(1-\frac{l}{b}\right)\left(2.15-3.93 \frac{l}{b}+2.7\left(\frac{l}{b}\right)^{2}\right)}{\left(1+2 \frac{l}{b}\right)\left(1-\frac{l}{b}\right)^{\frac{3}{2}}}$

where $\Delta \sigma$ is the range of applied stress amplitude, $l$ is crack length and $b$ is specimen height.

\section{Experimental results}

\subsection{Microstructure, microhardness, residual stress and tensile strength}

The microstructure at the five examined locations is of similar feature and Fig. 3 shows a set of microstructure images for the gradient layer. At the location just underneath the surface, the microstructure is tempered martensite (Fig. 3(a) and (b)). Then the small domains of pearlite and ferrite gradually appear in between the martensite colonies from $2.5 \mathrm{~mm}$ to $4 \mathrm{~mm}$ from the surface (Fig. 3(c)-(f)). At the depth of $6 \mathrm{~mm}$, the microstructure consists of almost equiaxed ferrite and distributed pearlite (Fig. 3(g)). Beyond $6 \mathrm{~mm}$ from surface, the microstructure is a mixture of coarse ferrite and pearlite (Fig. 3(h)), which is the original microstructure feature of the material.

The result of microhardness at different depths obtained from 5 samples is shown in Fig. 4(a). The average value of hardness keeps constant of $580 \mathrm{Hv}$ at the depth between $0 \mathrm{~mm}$ and $2 \mathrm{~mm}$ from surface, and then dramatically drops to $200 \mathrm{Hv}$ at the depth of $6 \mathrm{~mm}$.

The result of residual stress as a function of the depth from hardened surface is shown in Fig. 4(b), in which each datum point is the average value of 3 specimens. The maximum compressive residual stress presents at the depth of about $1.5 \mathrm{~mm}$ from the surface for all four types of specimens, and the value for the SAL specimen with notch is $-173 \mathrm{MPa}$, for the SAL specimen without notch is $-214 \mathrm{MPa}$, for the CAL specimen with notch is $-124 \mathrm{MPa}$ and for the CAL specimen without notch is $-174 \mathrm{MPa}$, respectively. It is seen that the residual stress rapidly increases from compressive state to zero at about $5 \mathrm{~mm}$ depth from surface for SAL specimens and at about $4 \mathrm{~mm}$ depth from surface for CAL specimens and then become tensile residual stress state. The values and the distribution trend of residual stress for the specimens with and without induced notch are similar, which implies that the presence of such a small notch on the specimen has little effect on the residual stress state for the present case.

Fig. 5(a) shows the results of one typical tensile curve for each depth from $0.5 \mathrm{~mm}$ to $7.5 \mathrm{~mm}$ from surface. It is seen that the strength is the highest at $0.5 \mathrm{~mm}$ and it declines evidently to $7.5 \mathrm{~mm}$ in depth, and that the plastic deformation ability increases substantially from the location of $0.5 \mathrm{~mm}$ to $7.5 \mathrm{~mm}$ from surface. The average value of tensile strength $\left(\sigma_{\mathrm{b}}\right)$ at each depth is shown in Fig. 5(b). From surface to $2 \mathrm{~mm}$ depth, the tensile strength is $1650 \mathrm{MPa}$ and it declines to $600 \mathrm{MPa}$ at $6 \mathrm{~mm}$ depth. Fig. 5(b) also shows the results of microhardness. It is seen that the variation trend of microhardness away from surface is similar to that of $\sigma_{\mathrm{b}}$, and the value of $\sigma_{\mathrm{b}}$ is about three times of microhardness (Hv) numerically.

\subsection{Fatigue crack growth rate by $C A L$}

Four CAL specimens were tested to measure the fatigue crack growth rate from the gradient layer to the interior matrix of the test material. The stress amplitude was $300 \mathrm{MPa}$ for CAL1 and CAL2, $310 \mathrm{MPa}$ for CAL3, and $320 \mathrm{MPa}$ for CAL4, respectively, which enabled the value of $\Delta K$ always above the threshold value during crack growth. The results of $\mathrm{d} a / \mathrm{d} N$ versus $\Delta K$ for CAL specimens are shown in Fig. 6 .

It is seen from Fig. 6(a) that the datum trend for 4 specimens is quite stable. Fig. 6(b) shows the value of $\mathrm{d} a / \mathrm{d} N$ versus $\Delta K$ in the groupings of 3 ranges of depth from surface. For the range of $0-2 \mathrm{~mm}$ depth, the fatigue crack growth rate increases from $5 \times 10^{-9} \mathrm{~m} /$ cycle to $1 \times 10^{-8}$ $\mathrm{m} /$ cycle with crack growth, and then slows down slightly. The fatigue crack growth rate keeps declining to $1 \times 10^{-9} \mathrm{~m} /$ cycle as the crack length growth between 2 and $3 \mathrm{~mm}$ depth. The fatigue crack growth is evidently resisted in the gradient microstructure layer. After $3 \mathrm{~mm}$ depth from surface, the fatigue crack growth rate increases monotonically with $\Delta K$. The Paris equation for the data after $3 \mathrm{~mm}$ depth from surface is fitted as Eq. (3). 

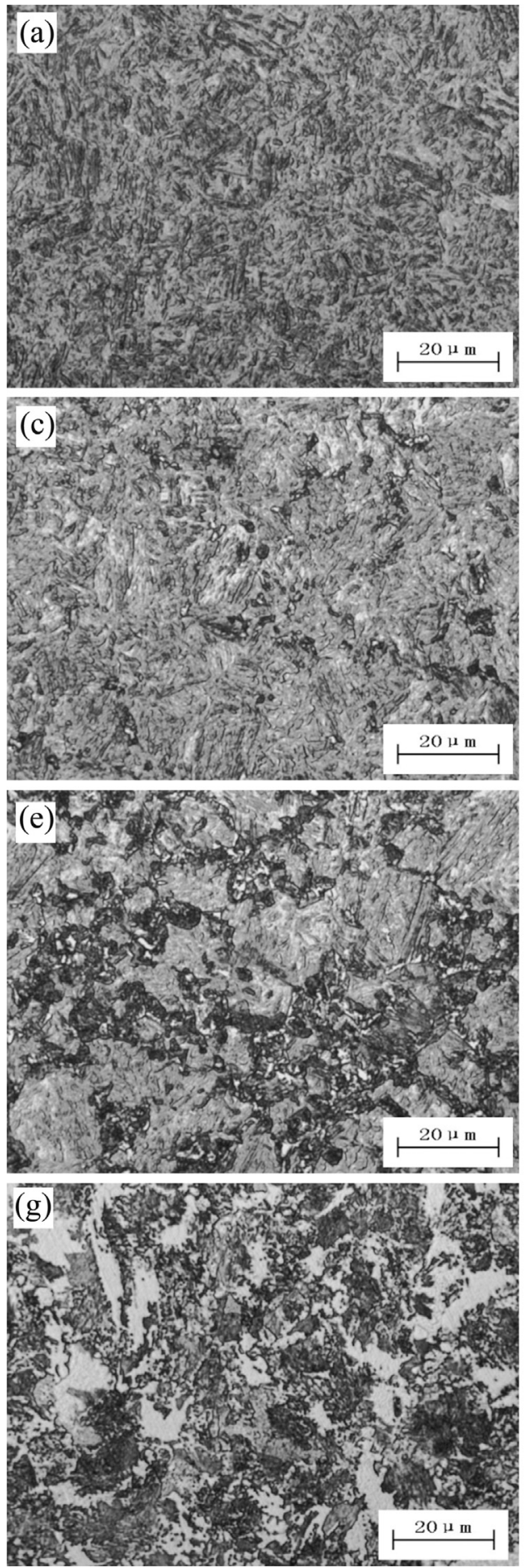
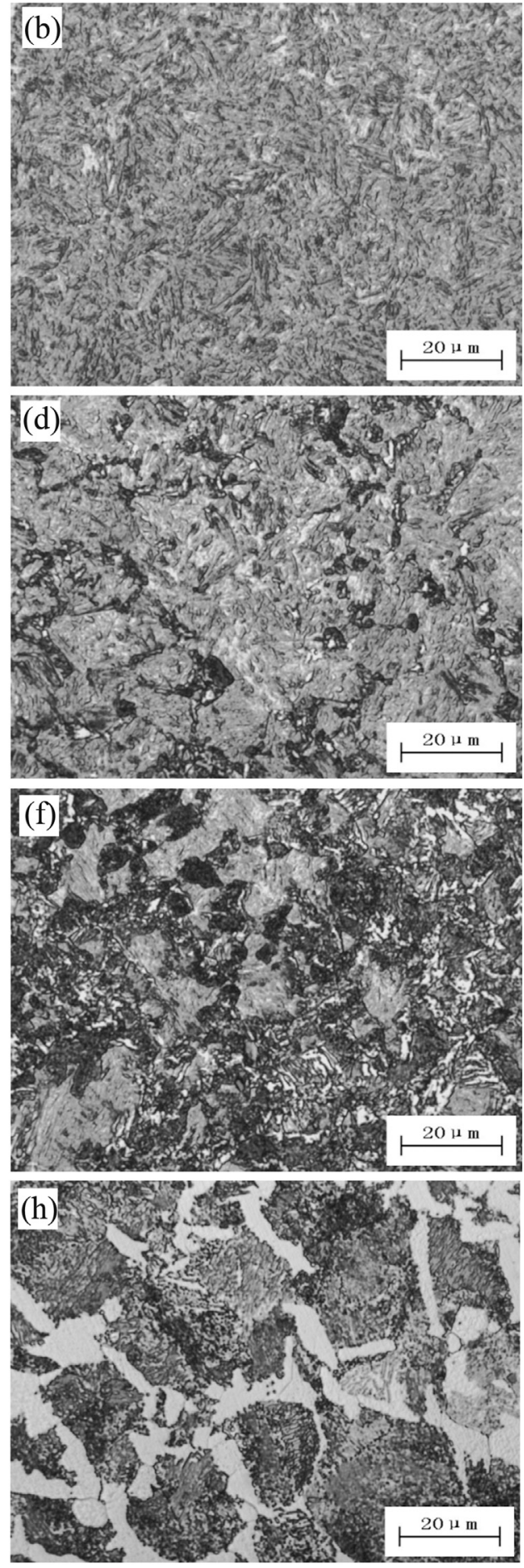

Fig. 3. Microstructure at different depths from surface: (a) $0.04 \mathrm{~mm}$, (b) $1 \mathrm{~mm}$, (c) $2 \mathrm{~mm}$, (d) $2.5 \mathrm{~mm}$, (e) $3 \mathrm{~mm}$, (f) $4 \mathrm{~mm}$, (g) $6 \mathrm{~mm}$ and (h) $8 \mathrm{~mm}$.

$\frac{\mathrm{d} a}{\mathrm{~d} N}=2.14 \times 10^{-21}(\Delta K)^{8.35}$

where the dimension of $\mathrm{d} a / \mathrm{d} N$ is $\mathrm{m} /$ cycle and that of $\Delta K$ is $\mathrm{MPa} \mathrm{m}^{1 / 2}$.

\subsection{Fatigue crack growth rate by $S A L$}

Nine specimens were tested with SAL loading for the measurement of fatigue crack growth rate. As an example, Fig. 7 shows the in-situ observations of fatigue crack growth for SAL1 specimen and Fig. 8(a) is the result of its $\mathrm{d} a / \mathrm{d} N-\Delta K$ curve. Each point in Fig. 8(a) presents the $\mathrm{d} a$ / $\mathrm{d} N-\Delta K$ value at a given depth. The arrow in Fig. 8(a) indicates the crack at the depth location of $3 \mathrm{~mm}$; the points on its left side are the cracks shorter than $3 \mathrm{~mm}$ and those on its right side are longer than $3 \mathrm{~mm}$. We can see from Fig. 8(a) that the fatigue crack growth rate decreases and the crack even stops growing within the range of $3 \mathrm{~mm}$ depth. After $3 \mathrm{~mm}$ depth from surface, the fatigue crack growth rate increases monotonically with the value of $\Delta K$. This phenomenon, usually called crack arrest, has been noticed and analyzed in short fatigue crack cases.

Performing like this for others, we acquired the data of $\mathrm{d} a / \mathrm{d} N$ as a function of $\Delta K$ for all nine specimens, and plotted the fatigue crack growth data to show in Fig. 8(b)-(d). The data from $0.5 \mathrm{~mm}$ to $2 \mathrm{~mm}$ depth from surface are shown in Fig. 8(b) in three groups at different 

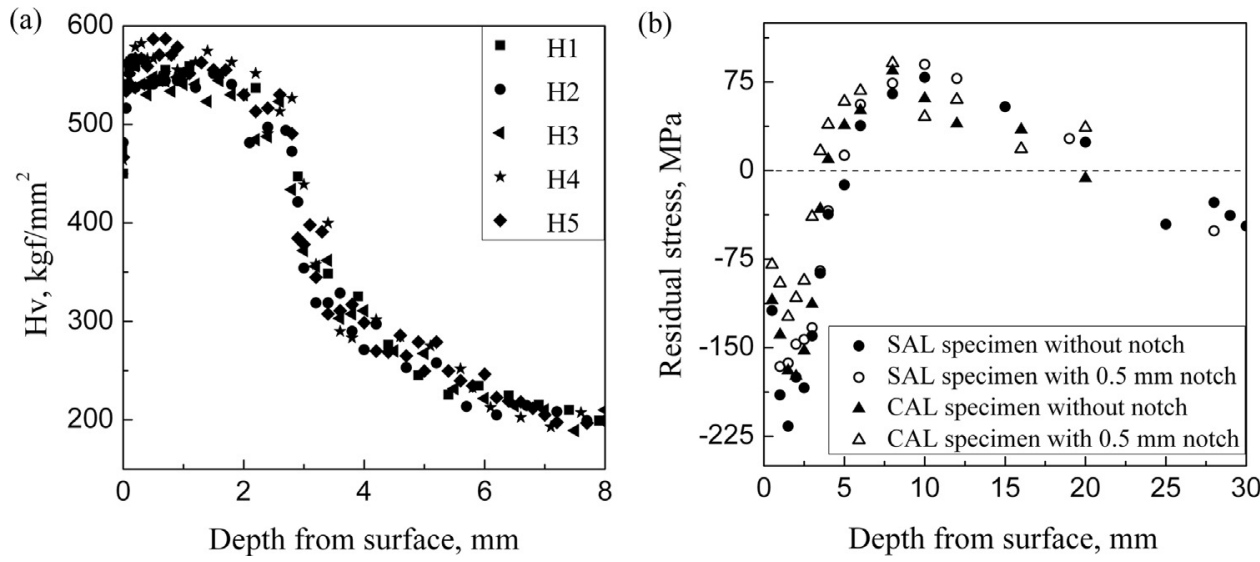

Fig. 4. (a) Values of hardness as a function of depth from surface and (b) values of residual stress as a function of depth from surface.

depths. It is obvious that the values of fatigue crack growth rate at a deeper depth are more on the right side, which means a higher threshold value of $\Delta K\left(\Delta K_{\text {th }}\right)$ and a lower fatigue crack growth rate for the location of a deeper depth under the same loading amplitude. The data of fatigue crack growth rate at the gradient layer from $2 \mathrm{~mm}$ to $6 \mathrm{~mm}$ depth are shown as three groups in Fig. 8(c). The data of crack growth rate after $6 \mathrm{~mm}$ depth are shown in Fig. 8(d), presenting the datum group of $6 \mathrm{~mm}$ to $9 \mathrm{~mm}$ almost matches the group beyond $9 \mathrm{~mm}$. It is seen that crack growth resistance near surface (0-2 $\mathrm{mm}$ depth) is higher than that in interior from Fig. 8(b) and (d).

It is obvious that fatigue crack growth rate is depth-dependent from Fig. 8(b)-(d). In order to further describe the fatigue crack growth rate of the material with gradient microstructure, a modified Paris equation containing the variation of depth $X$ is proposed

$\frac{\mathrm{d} a}{\mathrm{~d} N}=C(X)(\Delta K)^{n(X)}$

where $C$ and $n$ are material constants and $X$ is the depth from surface.

According to Eq. (4), we were able to plot a curved surface to correlate the values of $\Delta K, X$ and $\mathrm{d} a / \mathrm{d} N$ via the data of nine specimens by linear interpolation method, which is shown in Fig. 9.

Based on the fatigue crack growth data, we get the curved surface which links the fatigue crack growth rate, $\Delta K$ and the depth from surface together. This curved surface gives a good description of the fatigue crack growth behavior for the material with gradient microstructure and residual stress. This type of result is not seen in other investigations. Every point on the curved surface shows the fatigue crack growth rate at a given depth and under a certain value of $\Delta K$. Therefore the fatigue crack growth behavior can be described according to the curved surface. In the light of this, the residual life of a given case can be calculated by the integral of Eq. (4).

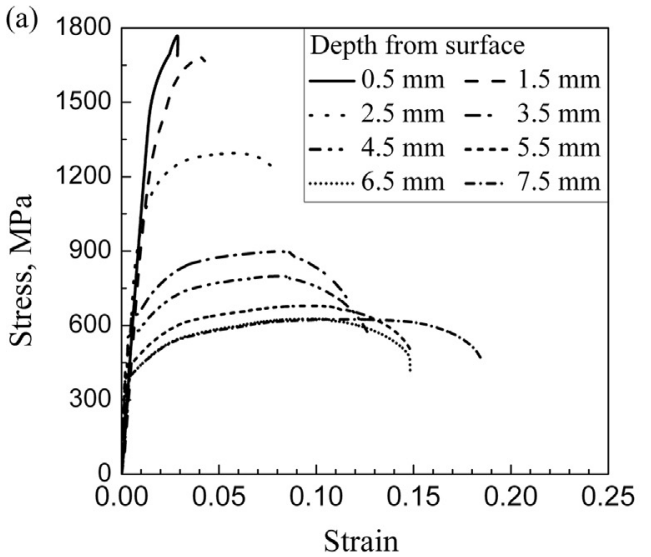

\section{Discussion}

\subsection{Crack arrest}

Crack arrest phenomenon in such a notch-crack situation is a distinct feature in the material with gradient microstructure. It means that surface strengthened material with a gradient microstructure layer has advantage in fatigue crack resistance. If the threshold value of fatigue crack growth is regarded as $1 \times 10^{-10} \mathrm{~m} /$ cycle in the curved surface shown in Fig. 9, the curve of $\Delta K_{\text {th }}$ as a function of $X$ can be drawn as Fig. 10. With the increasing of the depth from surface, the value of $\Delta K_{\text {th }}$ increases from $14 \mathrm{MPa} \mathrm{m}^{1 / 2}$ to $27 \mathrm{MPa} \mathrm{m}^{1 / 2}$ first and then drops to $6 \mathrm{MPa} \mathrm{m}{ }^{1 / 2} . \Delta K_{\text {th }}$ reaches the maximum value at about $2.5 \mathrm{~mm}$ depth from surface.

The value of $\Delta K$, which increases in accordance with Eq. (1), is more and more close to the threshold value $\Delta K_{\text {th }}(X)$ with the increment of the crack length in the range of $2.5 \mathrm{~mm}$ depth. Hence, there are two cases in the fatigue crack growth process under constant stress amplitude. For the specimens subjected to low stress amplitude indicated as the lower dotted curve in Fig. 10, the value of $\Delta K$ will drop below the threshold value $\Delta K_{\text {th }}(X)$ and the fatigue crack will stop growing. For the specimens subjected to high stress amplitude indicated as the upper dotted curve in Fig. 10, the value of $\Delta K$ will always keep above the threshold value. For the latter case, fatigue crack growth rate will drop a little, but the growth will not stop. As previously mentioned, both cases of low and high stress amplitude conditions indicated in Fig. 10 prevailed in the present investigation.

Fig. 5. (a) Stress-strain curves for tensile test at different depths and (b) average tensile strength and average hardness at different depths.

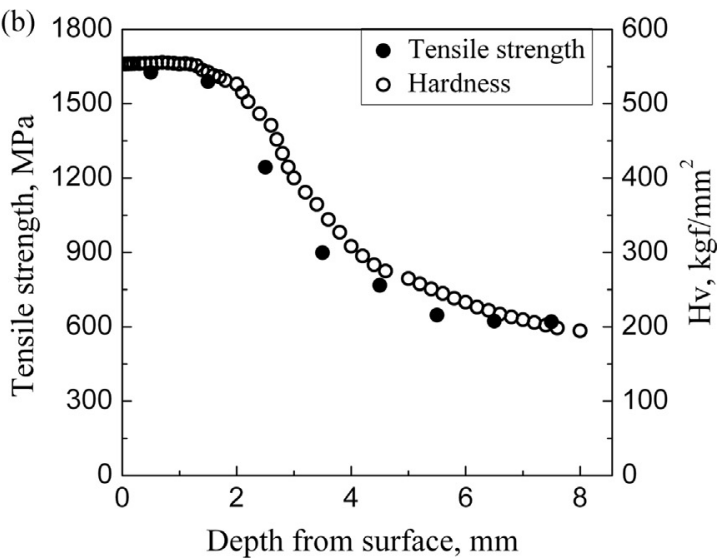



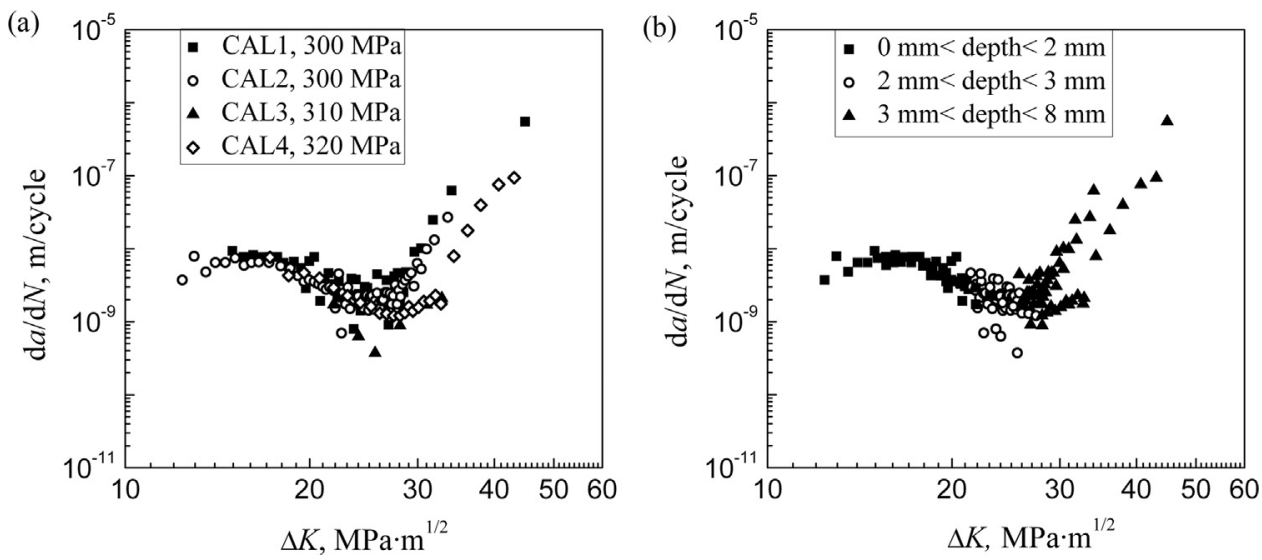

Fig. 6. Experimental results of $\mathrm{d} a / \mathrm{d} N$ versus $\Delta K$ for CAL specimens. (a) Data grouping for 4 specimens and (b) data grouping for 3 ranges of depth.

\subsection{Residual stress effect}

The relaxation of residual stress during fatigue loading process for surface hardened material is an important aspect [32-35], which will substantially affect the behavior of fatigue crack growth. In the analysis, the compressive residual stress at specimen surface is treated as superimposed mean stress for the present case. Thus, the value of $\Delta K$ calculated by Eq. (1) is modified by the effective value of $\Delta K\left(\Delta K_{\text {eff }}\right)$ as Eq. (5) [36].

$\Delta K_{\mathrm{eff}}= \begin{cases}\left(\sigma_{\mathrm{max}}+\sigma_{\mathrm{res}}\right) \sqrt{l} \cdot f\left(\frac{l}{b}\right), & \sigma_{\mathrm{res}}+\sigma_{\mathrm{min}}<0 \\ \left(\sigma_{\mathrm{max}}-\sigma_{\mathrm{min}}\right) \sqrt{l} \cdot f\left(\frac{l}{b}\right), & \sigma_{\mathrm{res}}+\sigma_{\min } \geq 0\end{cases}$

where $\sigma_{\max }$ is the maximum stress, $\sigma_{\min }$ is the minimum stress, $\sigma_{\text {res }}$ is residual stress, $l$ is crack length and $b$ is specimen height.

According to Eq. (5), the curve of $\Delta K_{\text {th,eff }}$ versus the depth from surface is plotted as Fig. 11(a). The value of $\Delta K_{\text {th,eff }}$ stays as approximately $8 \mathrm{MPa} \mathrm{m}{ }^{1 / 2}$ from $0.5 \mathrm{~mm}$ to $2 \mathrm{~mm}$ depth form surface. This value coincides with many experimental data of $\Delta K_{\text {th }}$ for martensitic steels. Between $2 \mathrm{~mm}$ and $3.5 \mathrm{~mm}$ depth from surface, $\Delta K_{\text {th,eff }}$ rapidly increases and then decreases slightly, which has the same trend with $\Delta K_{\text {th }}$. Beyond $3.5 \mathrm{~mm}$ depth from surface, the value of $\Delta K_{\text {th,eff }}$ almost merges with that of $\Delta K_{\mathrm{th}}$. Thus, it is seen that the existence of compressive residual stress makes the value of $\Delta K_{\text {th }}$ almost be twice as much as the case free of residual stress. Further, the effect of residual stress on fatigue crack growth rate for CAL tests is shown in Fig. 11(b). It is seen that the values of $\mathrm{d} a / \mathrm{d} N$ due to $\Delta K_{\text {eff }}$ are evidently smaller than those due to $\Delta K$ at the same depth in the range between 0 and $3 \mathrm{~mm}$ from surface, and this difference diminishes beyond $3 \mathrm{~mm}$ from surface, implying that the existence of compressive residual stress makes fatigue crack difficult to propagate. The results shown in Fig. 11 indicate that the trend for $\Delta K_{\text {th }}$ versus depth from surface and for $\mathrm{d} a / \mathrm{d} N$ versus $\Delta K$ is not changed due to residual stress, suggesting that the existence of residual stress has little influence on crack arrest phenomenon.

\subsection{Notch effect}

Short fatigue crack behavior should be considered in the early

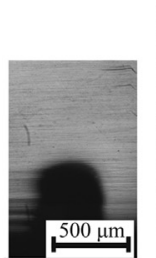

(a)

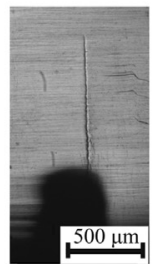

(b)

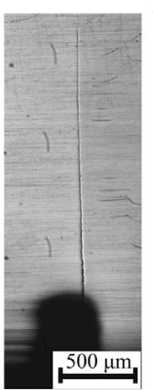

(c)

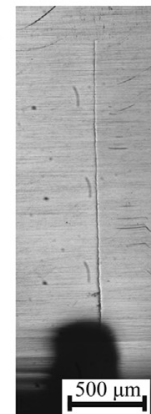

(d)

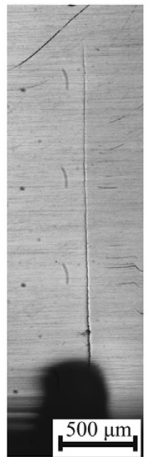

(e)

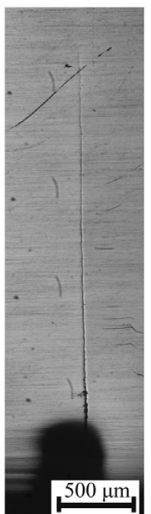

(f)

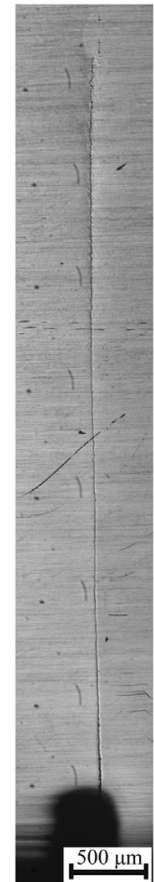

(g)

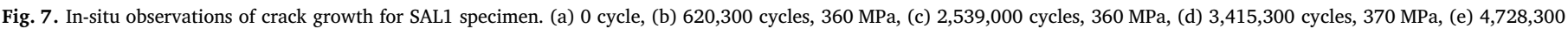
cycles, $380 \mathrm{MPa}$, (f) 5,374,000 cycles, $400 \mathrm{MPa}$ and (g) 6,533,100 cycles, $400 \mathrm{MPa}$. 

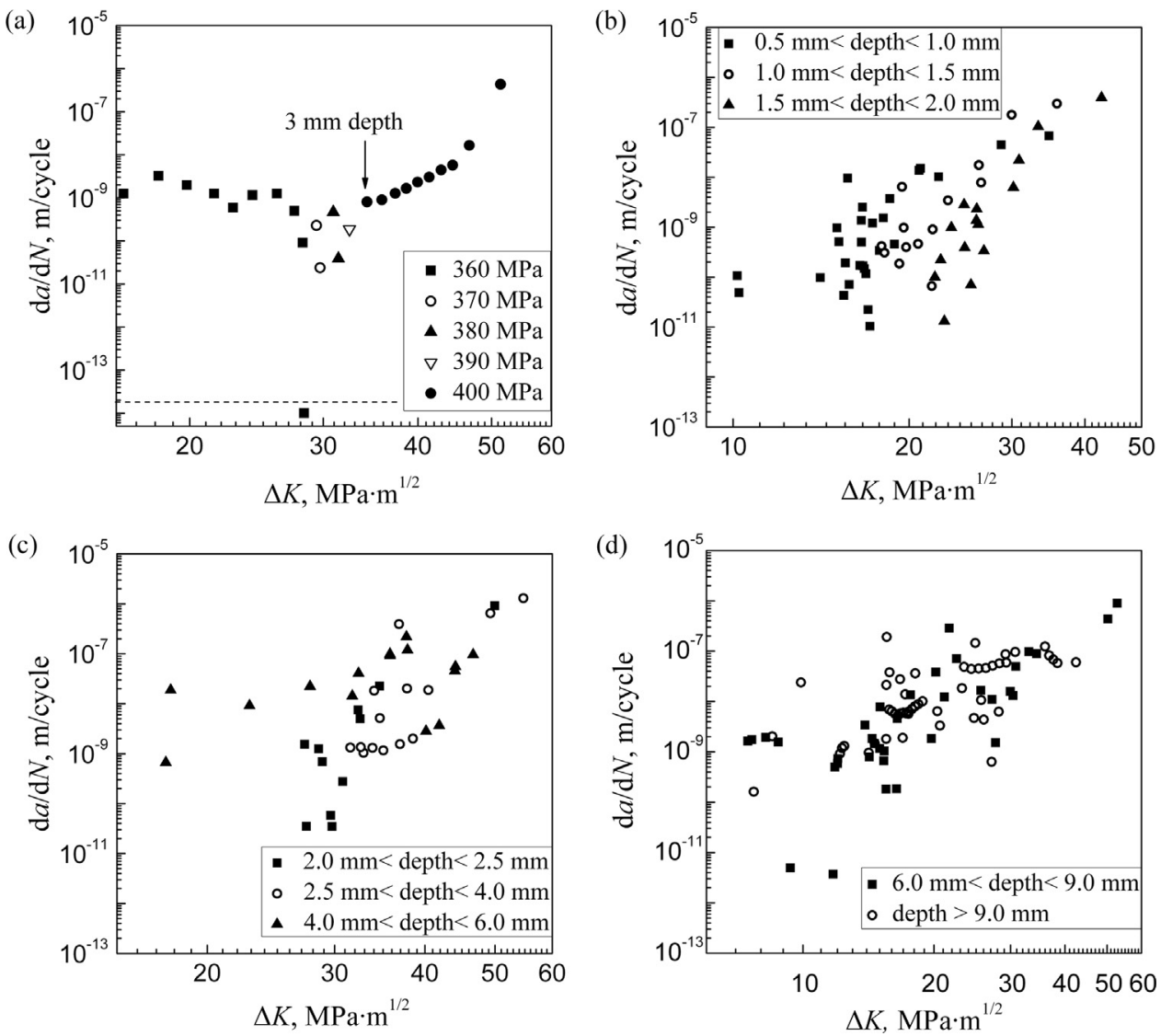

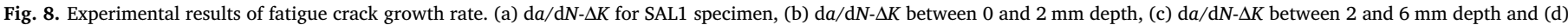
$\mathrm{d} a / \mathrm{d} N-\Delta K$ after $6 \mathrm{~mm}$ depth.

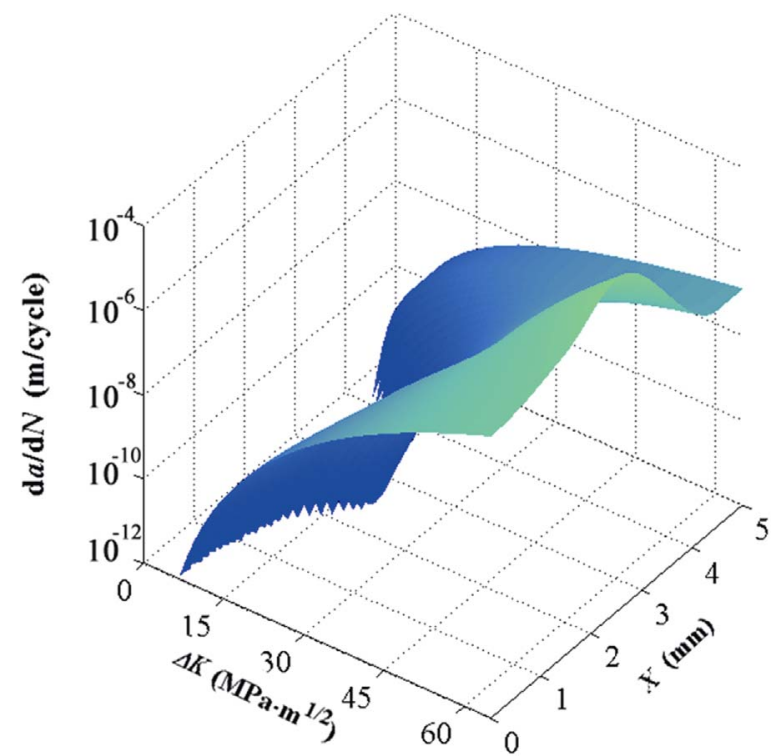

Fig. 9. A curved surface showing $\mathrm{d} a / \mathrm{d} N$ as a function of $X$ and $\Delta K$.

fatigue crack growth for the material with gradient microstructure [37-39]. It was regarded that the length of microstructurally short fatigue crack was approximately ten times of related grain size [40,41]. In the present investigation, every specimen for fatigue crack growth testing is with a notch at the hardened surface. Under a certain cyclic loading condition, fatigue crack may decelerate and even stop in the vicinity of the notch root. Afterwards when the fatigue crack grows to reach a critical length $\left(l_{0}\right)$, the effect of notch $\left(K_{\text {INotch }}\right)$ weakens and the value of $K_{\mathrm{I}}$ begins to dominate the fatigue crack growth.

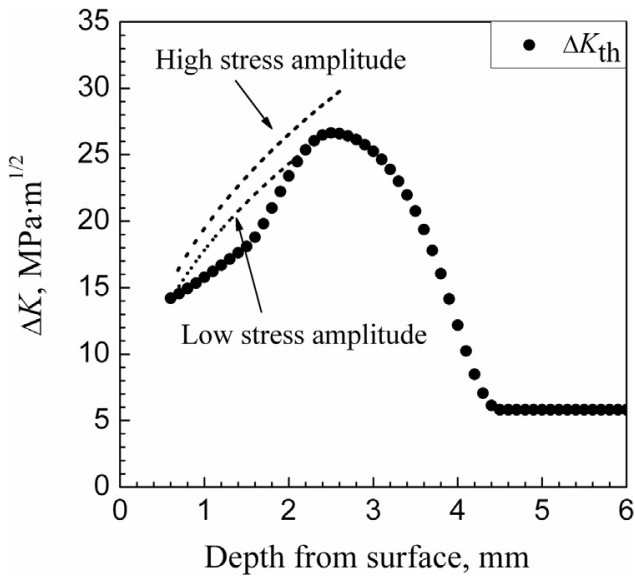

Fig. 10. Values of $\Delta K_{\text {th }}$ as a function of depth from surface.

In order to determine the value of $l_{0}$, we used the model for a rectangular specimen containing a surface notch subjected to tensile loading. The value of $K_{\mathrm{I}}$ at the crack tip for the rectangular specimen without notch is calculated by Eqs. (6) and (7) [31].

$K_{\mathrm{I}}=\sigma \sqrt{\pi l} F\left(\frac{l}{b}\right)$

$F\left(\frac{l}{b}\right)=1.122-0.231\left(\frac{l}{b}\right)+10.550\left(\frac{l}{b}\right)^{2}-21.710\left(\frac{l}{b}\right)^{3}+30.382\left(\frac{l}{b}\right)^{4}$

where $K_{\mathrm{I}}$ is the stress intensity factor of model I crack, $\sigma$ is nominal stress, $l$ is the length of fatigue crack and $b$ is the width of specimen.

For the specimen with notch, we assume the notch is elliptic shape. 

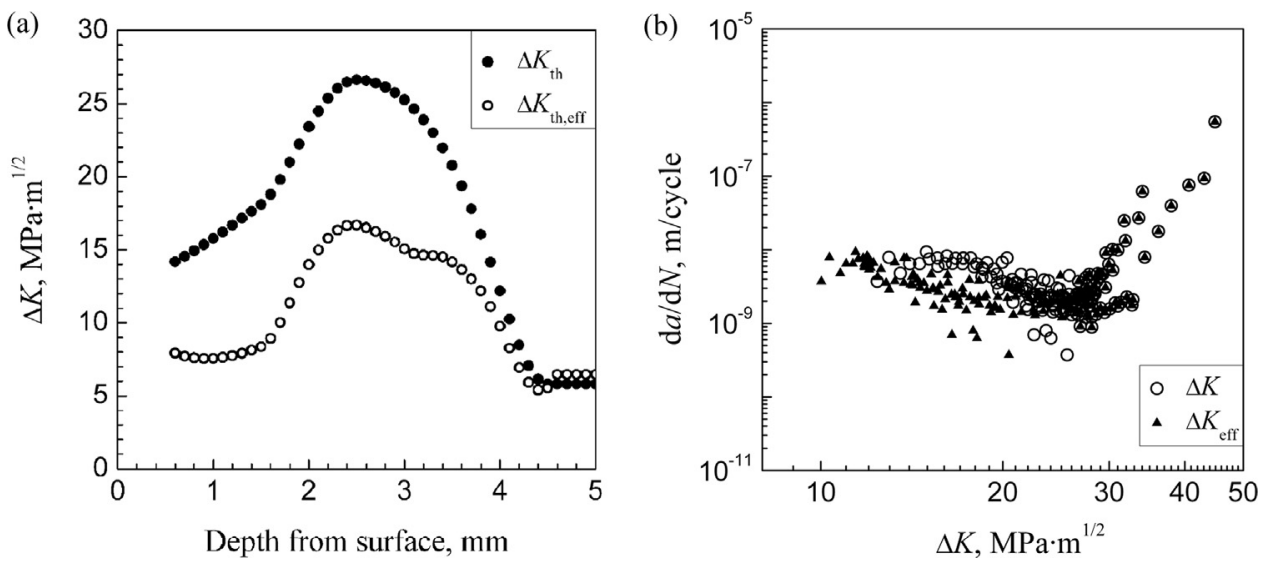

Fig. 11. (a) Values of $\Delta K_{\text {eff,th }}$ and $\Delta K$ as a function of depth from surface and (b) values of $\mathrm{d} a / \mathrm{d} N$ as a function of $\Delta K_{\text {eff }}$ and $\Delta K$ for CAL specimens.

Thus, Eqs. (8) and (9) [31,42] give the way to calculate the value of $K_{\mathrm{I}}$ for the notch specimen $\left(K_{\mathrm{INotch}}\right)$.

$K_{\text {INotch }}=\sigma \sqrt{\pi l} F_{\text {Notch }}$

$F_{\text {Notch }}=m+\frac{n}{l-h}$

where $F_{\text {Notch }}$ is the shape parameter, $\sigma$ is nominal stress and $l$ is the length of fatigue crack.

For the present investigation, the notch depth is $0.5 \mathrm{~mm}$ and the notch width is $0.4 \mathrm{~mm}$, so the parameters in Eq. (9) are $m=1.132, n=$ $0.287 \mathrm{~mm}$ and $h=0.4 \mathrm{~mm}$. The critical length $l_{0}$ should satisfy $K_{\mathrm{I}}=$ $K_{\text {INotch. }}$ Thus we obtained the value of $l_{0}$ as $0.7 \mathrm{~mm}$ by numerical calculation. It means that fatigue crack growth is controlled by $K_{\text {INotch }}$ from surface to about $0.7 \mathrm{~mm}$ depth. Within $0.7 \mathrm{~mm}$ depth, when the value of $K_{\text {INotch }}$ drops below $\Delta K_{\text {th }}$ with the increment of the fatigue crack length, the crack arrest will happen.

It should be noted that in the range of $0.7 \mathrm{~mm}$ from surface, the process of crack growth deceleration and arrest is due to the couple effect of notch short crack and compressive residual stress, and beyond $0.7 \mathrm{~mm}$ to $3 \mathrm{~mm}$ from surface, the process of crack growth deceleration and arrest is mainly resulted by the gradient microstructure with large compressive residual stress.

\subsection{Crack tip plasticity}

In the process of cyclic loading, a plastic zone will form at crack tip, which may introduce residual stress at the crack tip and result in crack closure. The size of crack-tip plastic zone and the opening displacement at the crack tip are calculated by Eqs. (10) and (11) for plane strain condition $[31,42]$.

$r_{\mathrm{p}}=\frac{K_{\mathrm{I}}^{2}}{6 \pi \sigma_{\mathrm{y}}^{2}}$

$\delta=\frac{4 K_{\mathrm{I}}^{2}}{\pi E \sigma_{\mathrm{y}}}$

where $r_{\mathrm{p}}$ is the size of crack-tip plastic zone, $\delta$ is the opening displacement at crack tip, $E$ is Young's modulus, $\nu$ is Poisson ratio, $\sigma_{\mathrm{y}}$ is yield strength and $K_{\mathrm{I}}$ is the stress intensity factor of model I crack.

At the gradient layer, the microstructure transforms from martensite to pearlite and ferrite (Fig. 3), and the yield strength drops dramatically and the material becomes more ductile (Fig. 5). According to Eqs. (10) and (11), both the loading level and the material properties influence the value of plastic zone size and crack opening displacement. The estimations showed that, under the same loading condition, the value of $r_{\mathrm{p}}$ at $3 \mathrm{~mm}$ depth is 2.5 times of that at $2 \mathrm{~mm}$ depth and the value of $\delta$ at $3 \mathrm{~mm}$ depth is 1.5 times of that at $2 \mathrm{~mm}$ depth, respectively, which means that the plastic zone size and the crack opening displacement increase rapidly as the fatigue crack growing through the gradient layer (from hardened surface gradually to the original microstructure). Hence the value of crack closure stress is possibly increased due to large plastic deformation during fatigue crack growth process. Thus, the reduction of yield strength and the increase of plasticity along the gradient layer are the major influential factors responsible for crack arrest phenomenon.

\section{Conclusions}

In this paper, an experimental investigation was performed on the fatigue crack growth behavior of an axle steel that contains a hardened surface layer with gradient microstructure. The main conclusions are summarized as follows:

(1) The microstructure of this material with surface gradient layer changes gradually from tempered martensite to small pearlite and ferrite surrounding martensite, and at last a mixture of coarse ferrite and pearlite. The material possesses high strength with large compressive residual stress at surface. The values of microhardness and tensile strength decrease with the depth away from surface, and the state of residual stress turns from high compressive stress into tensile stress.

(2) The surface strengthened gradient layer improves the fatigue resistance of the material, which is described by a constructed curved surface correlating the relationship among $\mathrm{d} a / \mathrm{d} N-\Delta K-X$ for the material with gradient microstructure. For the depth within $3 \mathrm{~mm}$ from surface, the value of $\Delta K_{\text {th }}$ increases from $14 \mathrm{MPa} \mathrm{m}^{1 / 2}$ to $27 \mathrm{MPa} \mathrm{m}{ }^{1 / 2}$. If the stress amplitude is not large enough, an initiated fatigue crack will arrest within $3 \mathrm{~mm}$ depth from surface due to the increase of the $\Delta K_{\text {th }}$ value.

(3) The state of compressive residual stress and the high strength resulted by the hardened gradient microstructure are responsible for the increase of $\Delta K_{\text {th }}$ within $3 \mathrm{~mm}$ depth from surface.

(4) In the range of $0.7 \mathrm{~mm}$ from surface, the process of crack growth deceleration and arrest is ascribed to the couple effect of notch short crack and compressive residual stress, and beyond $0.7 \mathrm{~mm}$ to $3 \mathrm{~mm}$ from surface, the process of crack growth deceleration and arrest is mainly resulted by the gradient microstructure with large compressive residual stress.

\section{Acknowledgements}

The authors wish to thank the financial supports by the National Natural Science Foundation of China (11572325) and by the Strategic Priority Research Program of the Chinese Academy of Sciences (XDB22040503, XDB22020201). 


\section{References}

[1] C. Laird, The fatigue limits of metals, Mater. Sci. Eng. 22 (1976) 231-236.

[2] M.K. Khan, Y.J. Liu, Q.Y. Wang, Y.S. Pyun, R. Kayumov, Effect of ultrasonic nanocrystal surface modification on the characteristics of AISI 310 stainless steel up to very high cycle fatigue, Fatigue Fract. Eng. Mater. Struct. 39 (2016) 427-438.

[3] A. Amanov, Y.S. Pyun, J.H. Kim, C.M. Suh, I.S. Cho, H.D. Kim, Q. Wang, M.K. Khan, Ultrasonic fatigue performance of high temperature structural material lnconel 718 alloys at high temperature after UNSM treatment, Fatigue Fract. Eng. Mater. Struct. 38 (2015) 1266-1273.

[4] U. Zerbst, C. Klinger, D. Klingbeil, Structural assessment of railway axles - A critical review, Eng. Fail. Anal. 35 (2013) 54-65.

[5] R. Fajkoš, R. Zima, B. Strnadel, Fatigue limit of induction hardened railway axles, Fatigue Fract. Eng. Mater. Struct. 38 (2015) 1255-1264.

[6] S. Prabhakaran, S. Kalainathan, Compound technology of manufacturing and multiple laser peening on microstructure and fatigue life of dual-phase spring steel, Mater. Sci. Eng. A 674 (2016) 634-645.

[7] T. Roland, D. Retraint, K. Lu, J. Lu, Fatigue life improvement through surface nanostructuring of stainless steel by means of surface mechanical attrition treatment, Scr. Mater. 54 (2006) 1949-1954.

[8] L. Yang, N.R. Tao, K. Lu, L. Lu, Enhanced fatigue resistance of $\mathrm{Cu}$ with a gradient nanograined surface layer, Scr. Mater. 68 (2013) 801-804.

[9] P. Zhang, J. Lindemann, Influence of shot peening on high cycle fatigue properties of the high-strength wrought magnesium alloy AZ80, Scr. Mater. 52 (2005) 485-490.

[10] C.K. Clarke, D. Halimunanda, Failure analysis of induction hardened automotive axles, J. Fail. Anal. Prev. 8 (2008) 386-396.

[11] N. Agarwal, H. Kahn, A. Avishai, G. Michal, F. Ernst, A.H. Heuer, Enhanced fatigue resistance in 316L austenitic stainless steel due to low-temperature paraequilibrium carburization, Acta Mater. 55 (2007) 5572-5580.

[12] B.Y. He, K.A. Soady, B.G. Mellor, G. Harrison, P.A.S. Reed, Fatigue crack growth behavior in the LCF regime in a shot peened steam turbine blade material, Int. J. Fatigue 82 (2016) 280-291.

[13] Y. Liu, M.Q. Wang, J. Shi, W.J. Hui, G. Fan, H. Dong, Fatigue properties of two case hardening steels after carburization, Int. J. Fatigue 31 (2009) 292-299.

[14] H.K. Akyildiz, M.K. Kulekci, U. Esme, Influence of shot peening parameters on highcycle fatigue strength of steel produced by powder metallurgy process, Fatigue Fract. Eng. Mater. Struct. 38 (2015) 1246-1254.

[15] H. Kristoffersen, P. Vomacka, Influence of process parameters for induction hardening on residual stress, Mater. Des. 22 (2001) 637-644.

[16] H. Mayer, Fatigue crack growth and threshold measurements at very high frequencies, Int. Mater. Rev. 44 (1999) 1-34.

[17] S. Stanzl-Tschegg, Very high cycle fatigue measuring techniques, Int. J. Fatigue 60 (2014) 2-17.

[18] S. Suresh, Fatigue of Materials, Cambridge University Press, 1991.

[19] W. Li, H. Deng, Z. Sun, Z. Zhang, L. Lu, T. Sakai, Subsurface inclusion-induced crack nucleation and growth behaviors of high strength steels under very high cycle fatigue: characterization and microstructure-based modeling, Mater. Sci. Eng. A 641 (2015) 10-20.

[20] D. Yin, H. Liu, Y. Chen, D. Yi, B. Wang, B. Wang, F. Shen, S. Fu, C. Tang, S. Pan, Effects of grain size on fatigue-crack growth in 2524 aluminium alloy, Int. J. Fatigue 84 (2016) 9-16.

[21] A. Trudel, M. Lévesque, M. Brochu, Microstructural effects on the fatigue crack growth resistance of a stainless steel CA6NM weld, Eng. Fract. Mech. 115 (2014) 60-72.

[22] T. Xu, Y. Feng, S. Song, D. Wang, Fatigue crack propagation behaviour of steels with different microstructures, Mater. Sci. Eng. A 551 (2012) 110-115.

[23] L. Li, Z. Zhang, G. Shen, The effect of grain size on fatigue crack propagation in commercial pure titanium investigated by acoustic emission, J. Mater. Eng. Perform. 24 (2015) 2720-2729.

[24] C. Blochwitz, R. Richter, Plastic strain amplitude dependent surface path of microstructurally short fatigue cracks in face-centred cubic metals, Mater. Sci. Eng. A 267 (1999) 120-129.

[25] M.T. Tilbrook, R.J. Moon, M. Hoffman, Crack propagation in graded composites, Compos. Sci. Technol. 65 (2005) 201-220.

[26] P. Gu, R.J. Asaro, Crack deflection in functionally graded materials, Int. J. Solids Struct. 34 (1997) 3085-3098.

[27] D.F. Martelo, A. Mateo, M.D. Chapetti, Crack closure and fatigue crack growth near threshold of a metastable austenitic stainless steel, Int. J. Fatigue 77 (2015) 64-77.

[28] S. Li, Y. Kang, S. Kuang, Effects of microstructure on fatigue crack growth behavior in cold-rolled dual phase steels, Mater. Sci. Eng. A 612 (2014) 153-161.

[29] S.G. Kravchenko, O.G. Kravchenko, C.T. Sun, A two-parameter fracture mechanics model for fatigue crack growth in brittle materials, Eng. Fract. Mech. 119 (2014) 132-147.

[30] K.S. Ravi Chandran, A physically based universal functional to characterize the mechanism of fatigue crack growth in materials, Scr. Mater. 107 (2015) 115-118.

[31] T. Hiroshi, P.C. Paris, G.R. Irwin, The Stress Analysis of Cracks Handbook, 58 ASME, New York, 2000.

[32] I. Cernýa, J. Sís, Fatigue strength of laser hardened 42CrMo4 steel considering effects of compressive residual stresses on short crack growth, Proc. Eng. 74 (2014) 417-420.

[33] O.S. Zaroog, A. Ali, B.B. Sahari, R. Zahari, Modeling of residual stress relaxation of fatigue in 2024-T351 aluminum alloy, Int. J. Fatigue 33 (2011) 279-285.

[34] S. Kodama, The behavior of residual stress during fatigue stress cycles, in: Proceedings of the International Conference on Mechanical Behavior of Metals II, Kyoto, Soc. Mater. Sci., 1972, pp. 111-118.

[35] J. Lu, D. Retraint, A review of recent developments and applications in the field of X-ray diffraction for residual stress studies, J. Strain Anal. 3 (2010) 127-136.

[36] C. Sun, Z. Lei, Y. Hong, Effects of stress ratio on crack growth rate and fatigue strength for high cycle and very-high-cycle fatigue of metallic materials, Mech. Mater. 69 (2014) 227-236.

[37] G.J. Deng, S.T. Tu, Q.Q. Wang, X.C. Zhang, F.Z. Xuan, Small fatigue crack growth mechanisms of 304 stainless steel under different stress levels, Int. J. Fatigue 64 (2014) 14-21.

[38] Y. Hong, Y. Lu, Z. Zheng, Short fatigue crack behaviour in iso-stress specimens, Acta Metall. Sin. 3 (1990) 276-281.

[39] I. Marines-Garcia, P.C. Paris, T. Hiroshi, C. Bathias, Fatigue crack growth from small to long cracks in VHCF with surface initiations, Int. J. Fatigue 29 (2007) 2072-2078.

[40] K.S. Ravi Chandran, Effects of crack aspect ratio on the behavior of small surface cracks in fatigue: part I. Simulation, Metall. Mater. Trans. A 28 (1997) 149-156.

[41] K.S. Ravi Chandran, J.M. Larsen, Effects of crack aspect ratio on the behavior of small surface cracks in fatigue Part II. Experiments on a titanium (Ti-8Al) alloy, Metall. Mater. Trans. A 28 (1997) 157-169.

[42] C. Bathias, A. Pineau, Fatigue of Materials and Structures, Wiley-ISTE, 2010. 